\title{
Regeneration and Transformation of Gene Encoding the Hemagglutinin Antigen of the H5N1 Virus in Frond of Duckweed (Spirodela polyrhiza L.)
}

\author{
Pham Thi Ly Thu, Pham Thi Huong, Vu Van Tien, Le Huy Ham \\ Agricultural Genetics Institute, Pham Van Dong Road, Tu Liem, Hanoi, Vietnam \\ Tran Dang Khanh (Corresponding author) \\ Agricultural Genetics Institute, Pham Van Dong Road, Tu Liem, Hanoi, Vietnam \\ Tel: 84-916-451-018Ｅ-mail: khanhkonkuk@gmail.com
}

Received: October 28, 2014 Accepted: November 14, 2014

doi:10.5296/jas.v3i1.6867ＵRL: http://dx.doi.org/10.5296/jas.v3i1.6867

\begin{abstract}
H5N1 (Avian influenza virus) has caused economic loss and remained a serious human health risk in many countries, including Vietnam. Plant-derived vaccines have offered the advantages over tradition subunit vaccine with low-cost production potential. Duckweed (Sprirodela polyrhiza L.) has found a valuable target plant for various application. In this study, we have attempted to re-generate and transform the gene encoding the hemagglutinin antigen of H5N1 virus in frond of $S$. polyrhiza, a widely great duckweed grown in Vietnam. The results have shown that the culture medium for $S$. polyrhiza duckweed is Hutner medium with reduced mineral concentration $1 / 2(\mathrm{H} / 2)$ supplemented with $10 \mathrm{~g} / 1$ sucrose at $\mathrm{pH} 6$. This medium showed appropriate for the best growth and development of duckweed. Results of PCR analysis of $S$. polyrhiza lines from 14 transformation experiments that has obtained 4 duckweed lines carrying $H A l$ gene. This prelinary results will be provide the basis for transgenic research in the dukweed species and be useful for further generate the producing enable vaccine via the transgenic plants
\end{abstract}

Keywords: Duckweed, H5N1, Vaccine, Transgenic plant

\section{Introduction}

H5N1 (Avian influenza virus) was first believed to cause disease only in poultry until the initial outbreak of highly pathogenic in humans in Asia in 1997. It has caused economic loss and 
remained a serious human health risk in many Asian countries, including China, Vietnam, Thailand, Korea, Indonesia, Japan etc. Hemagglutinin (HA), the principal viral surface antigen, is the primary target for neutralizing antibodies and is responsible for binding of the virus to host receptors, enabling entry into the host cell through endocytosis and subsequent membrane fusion (Stevens et al., 2006; Guo et al., 2012). In the trend of recent advanced biotechnology research have exhibited some achievements, including system for the production of desired vaccine antigen in transgenic plants (Floss et al., 2007). Plant-derived vaccines offer advantages over tradition subunit vaccine with low-cost production potential (Franconi et al., 2010). The duckweed (Lemnaceae) is a monocotyledonous family of five genera: Spirodela, Lemna, Landoltia, Wolffia and Wolfiella, and included over 37 species. Among them, Spirodela is the most ancestral, while Wolffia is the most derived (Les et al., 2002). All Lemnaceae species are small aquatic plants, free-floating, beneath or totally cover the furface of fresh water and wetlands, often forming dense, homogeneous clonal populations (Stomp, 2005). They proliferate primarily through vegetative budding of new fronds from parent fronds. Newly budded fronds remain attached to the parent frond to varying degrees, depending on species. Duckweeds have a worldwide distribution, especially temperate and tropical regions. The Lemna gibba L. and the Lemna minor L. are the most studied species of Lemnaceae family in phytoremediation and ecotoxicology (Mkandawire and Dudel, 2005).

Great duckweed (Spirodela polyrhiza L.) is belonging to the member of Lemnaceae family under the group monocotyledons. The individual plants range in size from $1.5 \mathrm{~cm}$ long and is a successive reduction of morphological structures in parallel with evolutionary advancement within the family (Wang et al., 2011). Great duckweed is one of important model system for research on plant biology, biofuel potential candidates, biomass utility, toxicity testing organism, biotech protein factories, wastewater remediation, high protein animal feeds, carbon cycling because of its fast growth, wide distribution, short life span and stability to environmental change (Stomp, 2005; Brain and Solomon, 2007; Ozengin and Elmaci, 2007; Rahman et al., 2007), particularly in biochemical studies S. polyrhiza is an ideal system for biofueld, bioremediation and carbon cycling due to their aspect of fast-growing direct contact with media and has the smallest genome size ( 150 Mb) (Wang et al., 2011; Wang et al., 2014). This aquatic plant consists of high mutrient uptakes rates, and is cold tolerant and less sensitive than other aquatic plants to high nutrient stress, droughts, pests and disease. It develops and grows well in water under the different climates at temperature between 6 to $33^{\circ} \mathrm{C}$, especially in tropical and temperate areas and obtains high biomass yield approximately 10-30 tons $\mathrm{DM} / \mathrm{ha} / \mathrm{year}$, containing high levels of crude protein up to 10 tons/ha/year with a good amino acid balance (Leng et al., 1995).

Vietnam is a tropical and subtropical country where the duckweeds, especially, S. polyrhiza is widely speading and growing in the streams, ponds and wetland areas. Its production plays a key role in this country, provides meat and eggs in the diet of people and income from local sale in domestic markets. Traditional vaccines are produced by applying fermentation technology in various cell culture systems. However, numerous limitation related to fermentation so that development of alternative systems for the production of vaccines is timely (Davoodi et al., 2009; Daniell et al., 2009; Gomez et al., 2010). 
Since duckweed is found a valuable target plant for various application, the feasibility of transformation of $S$. polyrhiza by Agrobacterium tumefaciens- mediated gene transfer may offer an extended range of application. In this study, we have attempted to re-generate and transform the gene encoding the hemagglutinin antigen of H5N1 virus in frond of S. polyrhiza, a widely great duckweed grown in Vietnam. The data should be useful for further generate the producing enable vaccine via the transgenic plant.

\section{Materials and Methods}

\subsection{Plant Materials}

Duckweeds were collected in the experimantal field of Agricultural Genetics Institute, Hanoi, Vietnam, and then cultured in the jar at nursery of Agricultural Genetics Institute. The samples were identified and confirmed as the S. polyrhiza by the method of Landolt (1986)

\subsection{Genetic Materials}

A. tumefaciens AGL-1 carrying p6d35S-UbiHA1 vector which containing selectable marker gene hpt (resistant hygromycin) and gene HAl encoding the hemagglutinin antigen of the $\mathrm{H} 5 \mathrm{~N} 1$ virus is under the control of the Ubiquitin promoter was used.

\subsection{In Vitro Starting Materials}

To make in vitro starting materials, $\mathrm{Ca}(\mathrm{OCl})_{2}$ with diffirent concentrations at 3,5 and $7 \%$, and with time duration was s 2,4 and 6 min to sterile the plants $S$. polyrhiza. After soaking with antiseptic chemmical, duckweed samples were rinsed many times by sterile water, then sucked dried and cultured on solid H/5 added $15 \mathrm{~g} / 1$ sucrose at $\mathrm{pH}$ 5.8. Each formula was used 100 cluster $S$. polyrhiza including 3 - 4 fronds/ cluster.

\subsection{Optimization of Culture Medium for Duckweed in In Vitro}

The basic medium for duckweed culture was conducted following the method of Hutner (1975) with some modifications. Briefly, the optimal culture medium for S. polyrhiza was prepared: Medium $\mathrm{H}$ was added $15 \mathrm{~g} / \mathrm{l}$ sucrose, $\mathrm{pH} 5.8$ with mineral content at ratios: 1/1;1/2; 1/3;1/4 and $1 / 5(\mathrm{H} ; \mathrm{H} / 2 ; \mathrm{H} / 3 ; \mathrm{H} / 4$ and $\mathrm{H} / 5)$. Medium H/2 (50\% mineral Hutner) was added $15 \mathrm{~g} / \mathrm{l}$ sucrose with variable medium $\mathrm{pH}$ at $4.0 ; 5.0 ; 6.0 ; 7.0 ; 8.0 ; 9.0$ and 10, respectively. Medium H/2 with sucrose concentrations was added $(0,10,20$ and $30 \mathrm{~g} / \mathrm{l})$. Duckweed was cultured in RUMED incubator, temperature at $26 \pm 2{ }^{\circ} \mathrm{C}$, humidity $80 \%$, photoperiod $10 / 24 \mathrm{~h}$.

\subsection{Method for Gene Transfer in Spirodela Polyrrhiza Mediated Agrobacterium}

The transformation protocol was performed by the method of Boehm et al (2001), with some minor modifications (Thu et al., 2010).

\subsubsection{Preparation of Agrobacterium Suspension}

Streak Agrobacterium from $-20^{\circ} \mathrm{C}$ stock (in glycerol) on solid LB medium with the appropriate antibiotics (kanamycin $50 \mathrm{mg} / \mathrm{l}$ and carbenicillin $50 \mathrm{mg} / \mathrm{l}$ ). The cultured growth was kept for 3 days at $28^{\circ} \mathrm{C}$ in darkness. Pick up single colonies and streak it on liquid $\mathrm{H} / 2$ medium (pH 5.6) added $200 \mu \mathrm{M}$ AS, shaking culture at $160 \mathrm{rpm}$ for $4-6 \mathrm{~h}$. Before inoculation with duckweed, the 
density of bacteria reached $\mathrm{OD}_{600} \approx 0.5-1.0$ was adjusted.

\subsubsection{Preparation of Duckweed Sample}

Three days prior to the transformation experiment, the duckweed should be cultured in the appropriate medium to assure the homogeneous of target materials. The culture medium of $S$. polyrhiza was $\mathrm{H} / 2+10 \mathrm{~g} / \mathrm{l}$ sucrose $+7 \mathrm{~g} / \mathrm{l}$ agar at $\mathrm{pH} 6.0$

\subsubsection{Infection and Cocultivation}

Infection stage was carried out in the effendorf tube including duckweed fronds with $1 \mathrm{ml}$ bacteria suspension. This mixture was centrifuged and vacuumed in $10 \mathrm{~min}$, then kept at room temperature for $20 \mathrm{~min}$. Cocutivation time between bacteria and duckweed sample was 3 days at $26^{\circ} \mathrm{C}$, humidity $85 \%$, light 3000 lux with photoperiod $12 / 24 \mathrm{~h}$.

\subsubsection{Removing Agrobacterium and Resting Culture}

After cocultivation, transfer the duckweed to resting medium which was growth medium of duckweed adding $200 \mathrm{mg} / \mathrm{l}$ timentin at $\mathrm{pH}$ 6. Subcultured on this medium from 2-3 cycles

\subsubsection{Selection of Transformed Duckweed}

After removing Agrobacterium and resting culture, the transformed duckweed frond to selection medium (Medium containing selective agent was hygromycin) was transfered. Maintain and subcultured transformed duckweed lines on selection medium from 3-5 cycles (5-7 days/cycle) were conducted with the selected medium was $\mathrm{H} / 2+5 \mathrm{mg} / \mathrm{l}$ hygromycin + $7 \mathrm{~g} / \mathrm{l}$ agar

\subsection{PCR Analysis of Transgenic Duckweed Lines}

The PCR was performed with the specific primers for hpt and HAl genes

Primer sequences:

Hpt- F- 5'- AGAAGAAGATGTTGGCGACCT-3'

Hpt- R- 5'- GTCCTGCGGGTAAATAGCTG-3'

T-HAl-for- 5'TACCCAGGGGATTTCAATGAC 3“

T-HAl-rev - 5'GACACTTGGTGTTGCAGTTAC 3“

\subsection{Evaluation of Factors}

Each experimental formula using 5 triangle vases contained $100 \mathrm{ml}$ medium with 20 cultured duckweed fronds. Counting duckweed frond total in 5 vases of every experimental formula after culture $24 \mathrm{~h}$. Experimental time was 6 days. Each experimental formula was repeated 3 times.

Frond multiplying rate (Landolt \& Kandeler, 1987) 


$$
\mathrm{k}_{\mathrm{ni}}=\frac{F d_{i}}{F d_{0}}
$$

(Of which $\mathrm{k}_{\mathrm{ni}}$ : Multiplication factor at the $\mathrm{i}$ day; $\mathrm{Fd}_{\mathrm{i}}$ : Total number of leaflike at $\mathrm{i}$ culture day; $\mathrm{Fd}_{0}$ : total leaflike in initial time)

\section{Results and discussion}

\subsection{Making in Vitro Starting Materials}

As shown in Table 1, the concentration and time duration showed significant influence on the ration of the steriled samples. The highest ration of uncontaminated sterile sample was $54 \%$ when applying decontaminated method $\mathrm{Ca}(\mathrm{OCl})_{2} 5 \%$ in 2 min. After sterilization, a part of around nodule point of duckweed frond died partially but $2-3$ late days appearing new duckweed frond growth from its meristem. The sterile method by applying $\mathrm{Ca}(\mathrm{OCl})_{2} 5 \%$ for 2 min to make in vitro starting materials for further studies.

Table 1. The effect of time and concentration $\mathrm{Ca}(\mathrm{OCl})_{2}$ to the ratio of steriled samples of $S$. polyrhiza

\begin{tabular}{|l|l|l|l|l|}
\hline \multirow{2}{*}{$\mathrm{Ca}(\mathrm{OCl}) 2(\%)$} & Time (minute) & $\begin{array}{l}\text { The ratio of } \\
\text { steriled sample }(\%)\end{array}$ & $\begin{array}{l}\text { The ratio of } \\
\text { contaminated sample (\%) }\end{array}$ & $\begin{array}{l}\text { The ratio of death } \\
\text { sample }(\%)\end{array}$ \\
\hline \multirow{3}{*}{3} & 2 & 28 & 55 & 17 \\
\cline { 2 - 5 } & 4 & 32 & 44 & 24 \\
\cline { 2 - 5 } & 6 & 46 & 29 & 25 \\
\hline \multirow{5}{*}{5} & 2 & 54 & 24 & 22 \\
\cline { 2 - 5 } & 4 & 41 & 20 & 39 \\
\cline { 2 - 5 } & 6 & 35 & 17 & 48 \\
\hline \multirow{5}{*}{7} & 2 & 32 & 20 & 64 \\
\cline { 2 - 5 } & 4 & 22 & 14 & 74 \\
\cline { 2 - 5 } & 6 & 15 & 11 & 64 \\
\hline
\end{tabular}

\subsection{Optimization of Culture Medium for Duckweed in Vitro}

To produce the starting materials for transformation which must be make optimal conditions for the growth and development of plant. The purpose of this experiment to determine the norm for the growth and development of duckweed as the reproductive characteristic, duplicate time and biomass multiplication factor in duckweed

\subsubsection{Effect of Hutner Mineral Content to the Growth and Development of S. polyrhiza}

Hutner mineral has been by many authors to multiply species belonging to Lemnaceae familia, especially Hutner medium with mineral component decrease 5 times (Landolt, 1986). Therefore, the aims of this experiment to find out the proportion of mineral Hutner suitable for the growth and development of S. polyrhiza. In order to select the appropriate mineral content for the growth and development of $S$. polyrhiza, the different mineral ratios: H (100\% Hutner mineral), H/2, H/3, H/4, H/5 were applied, the environmental disinfection before being 
adjusted to $\mathrm{pH}$ 5.8. The result was collected after $24 \mathrm{~h}$ culture in 6 days as shown in the Table 2 .

Table 2. Effect of Hutner mineral content to the frond multiplying rate in S. polyrhiza

\begin{tabular}{|l|l|l|l|l|l|l|l|}
\hline Cultute time (days) & 0 & 1 & 2 & 3 & 4 & 5 & 6 \\
\hline $\mathrm{H}$ & 1 & 1.41 & 1.89 & 2.82 & 3.63 & 4.23 & 4.78 \\
\hline $\mathrm{H} / 2$ & 1 & 1.40 & 1.83 & 2.53 & 3.89 & 4.87 & 5.32 \\
\hline $\mathrm{H} / 3$ & 1 & 1.40 & 1.74 & 2.27 & 3.28 & 3.96 & 4.55 \\
\hline $\mathrm{H} / 4$ & 1 & 1.38 & 1.69 & 2.14 & 3.02 & 3.50 & 4.40 \\
\hline $\mathrm{H} / 5$ & 1 & 1.38 & 1.56 & 2.23 & 2.58 & 3.34 & 4.23 \\
\hline
\end{tabular}

The results of Table 2 revealed that: In the first 3 days of culture, there was no significant difference between the formulas of experimental medium, but from fourth, there was significant difference between the medium formulations containing with different Hutner minerals content. The growth of duckweed S. polyrhiza was directly proportional with the rate of mineral in the culture medium. However, the growth and development of S. polyrhiza on the $\mathrm{H}$ medium (100\% Hutner mineral) less than $\mathrm{H} / 2$ (50 \% Hutner mineral) by overlaying fronds, which has not separated, affected to the growth and development of mother fronds, leading to deformed fronds, distortion.

After 6 days of culture, medium formula H/2 (50\% Hutner) for the speed of highest frond multiplying coefficient, reaching 5.32 times, duckweed growth and good development. Healthy duckweed frond, duckweed status similar duckweed living in a natural medium. Therefore, the mineral H/2 background for the next growing experiments was selected.

\subsubsection{Effect of $\mathrm{pH}$ Medium to the Growth and Development of S. Polyrhiza}

As the previous report of Landolt \& Kandeler (1987), S. polyrhiza could grow in medium with a $\mathrm{pH}$ from 3.7 to greater than 9 and grows well in the $\mathrm{pH}$ range from 4-7.With the aim of finding the most suitable $\mathrm{pH}$ for growth and development of $S$. polyrhiza in vitro culture conditions, we have conducted 7 experimental formula on mineral environment with $\mathrm{H} / 2+15$ $\mathrm{g} / 1$ sucrose with a $\mathrm{pH}$ instead ranging from 4-10. The obtained results indicated that $\mathrm{pH}$ ranging from 5.0 to 9.0 is appropriate for the growth and development of S. polyrhiza in laboratory conditions. While, $\mathrm{pH}$ lower 5.0 exhibited growth inhibition, aging duckweed and death very quickly. The appropriate $\mathrm{pH}$ showed remarkerble enhancement frond multiplying coefficient after 5-6 days of culture. The current data demonstrated that $S$. polyrhiza can grow and develop best at $\mathrm{pH}=6$, frond multiplier factor was 6.11 times after 6 days of culture, the morphological of duckweed frond in vitro was similar as ducweed growth in the nature condition. On the medium having $\mathrm{pH}>6$, thin duckweed frond, the wide and tend to lean towards the yellow. Therefore, culture medium with $\mathrm{pH}=6$ for our experiments in the next phase of growth was applied. In the report of Caiedo et al. (2000), the inhibition of duckweed growth by ammonium was found to be due to a combined effect of ammonium ions and depending on the $\mathrm{pH}$. In the previous research, Nguyen et al (2012) reported to successfully express an avian influenza HA protein in the Lemna auxotroph platform.

Table 3. Effect of $\mathrm{pH}$ medium to the frond multiplying rate in S. polyrhiza 


\begin{tabular}{|l|l|l|l|l|l|l|l|}
\hline pH Cultute time (days) & 0 & 1 & 2 & 3 & 4 & 5 & 6 \\
\hline 4 & 1 & 1.36 & 1.67 & 2.23 & 3.26 & 3.47 & 3.94 \\
\hline 5 & 1 & 1.55 & 1.92 & 2.64 & 4.10 & 4.94 & 5.20 \\
\hline 6 & 1 & 1.42 & 2.03 & 2.97 & 4.35 & 5.34 & 6.11 \\
\hline 7 & 1 & 1.50 & 2.25 & 3.37 & 4.38 & 5.22 & 5.79 \\
\hline 8 & 1 & 1.49 & 2.22 & 3.33 & 4.30 & 5.10 & 5.61 \\
\hline 9 & 1 & 1.48 & 2.32 & 3.46 & 4.43 & 5.01 & 5.41 \\
\hline 10 & 1 & 1.50 & 2.15 & 3.20 & 4.23 & 4.79 & 5.11 \\
\hline
\end{tabular}

\subsubsection{Effect of Sucrose Content to the Growth and Development of S. Polyrhiza}

Duckweed in general and in particular S. polyrhiza is capable of being autotrophic carbon so in medium have not sucrose, it is still able to grow and develop. Howerver, to create material source for experiments, nutrious medium was needed to provide sucrose so that duckweed could grow and develop at rapid speed, providing materials for buiding experiments about generation and transgenic systems and biomass production necessary for the purpose of producing large quantities.

The results have shown that there was of different levels in the tracking target about multiplying coefficient between sucrose supplement formulations and sucrose non-supplement formulations. This difference was greater when the longer incubation time, after 6 days of culture, the multiplier factor in the formula supplemented with $10 \mathrm{~g} / \mathrm{l}$ sucrose was 1.5 times higher to compare with non-supplemented formula sucrose (Table 4). Supplement formula $10 \mathrm{~g} / \mathrm{l}$ sucrose for speed and highest multiplying coefficient in culture process, reaching 6.31 times after 6 days of culture.

Table 4. Effect of sucrose content to the frond multiplying rate in S. polyrrhiza

\begin{tabular}{|c|c|c|c|c|c|c|c|}
\hline $\begin{array}{lll}\text { Sucrose }(\mathrm{g} / \mathrm{l}) & \text { Cultute time (days) }\end{array}$ & 0 & 1 & 2 & 3 & 4 & 5 & 6 \\
\hline 0 & 1 & 1.40 & 1.77 & 2.95 & 3.19 & 3.94 & 4.22 \\
\hline 10 & 1 & 1.43 & 2.31 & 3.35 & 4.65 & 5.55 & 6.31 \\
\hline 20 & 1 & 1.46 & 2.09 & 3.10 & 4.35 & 5.22 & 6.01 \\
\hline 30 & 1 & 1.42 & 1.92 & 2.91 & 4.01 & 4.94 & 5.65 \\
\hline
\end{tabular}


A

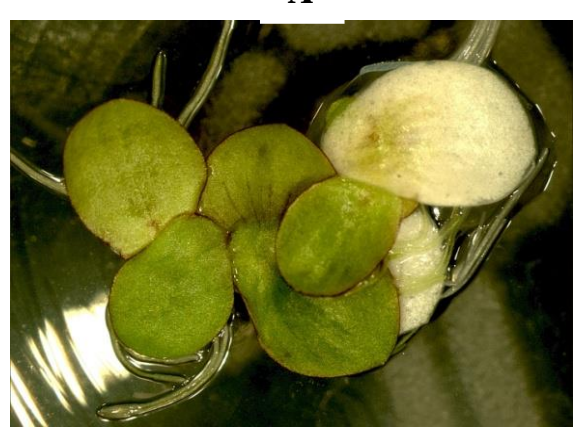

B

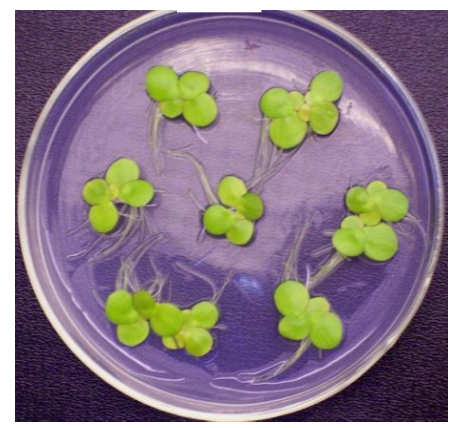

C

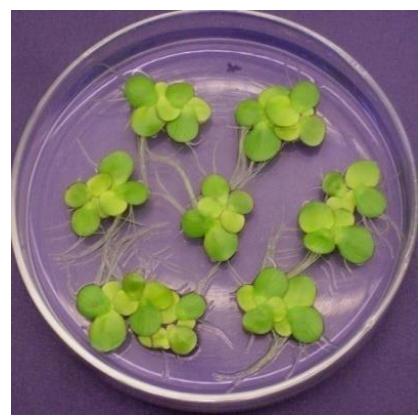

Figure 1. Fronds of $S$. polyrhiza after sterilization (A); new fronds were developed (B); growing on the medium $\mathrm{H} / 2+10 \mathrm{~g} / 1$ sucrose, $\mathrm{pH} 6.0$ (C).

In the other hand, culture medium for S. polyrhiza has reached the highest multiplying rate (6.31 times after 6 days of culture) which was $\mathrm{H} / 2$ medium additional $10 \mathrm{~g} / 1$ sucrose at $\mathrm{pH} 6.0$.

\subsection{Transformation of Gene Coding to Antigene of H5N1 Virus into S. Polyrhiza Mediated Agrobacterium Tumefaciens}

One of the factors that has stimulated the process of transferring T-DNA from A.tumefaciens bacteria into plant cells that damaged plant cells. When cells are hurt, it often secretes the phenolic compounds, these compounds have effected to attract bacteria. On the other way, the reproduction of ducweed is vegetative reproduction in the form daughter fronds are generated from the meristem of mother frond. Therefore, we conducted a sample pre-treatment before transformation to improve the efficiency of the gene transfer process.

S. polyrhiza sample was cultured on $\mathrm{H} / 2$ medium in 3 days to ensure equivalent - grade of experimental material. Then duckweed fronds was separated from the duckweed cluster and treated according to the method of vertical cut -off, cut through nodes, divided into 2 equal parts frond. Processing sample was then infected with $1 \mathrm{ml}$ of bacterial strains AGL-1 carrying A. tumefaciens p6d35S vector of centrifugal vacuum conditions ( $75 \mathrm{cmHg}, 1200 \mathrm{rpm}$ ), in 20 min. After infection, duckweed fronds picked out and cultured on co-cultured medium for 3 days. We have conducted a series of HAl antigen gene transferring experiments in transgenic duckweed SP. The results are presented in the Table 5. Also, some previous reports showed a reliable transformation protocol of member of the duckweed (Wolffia Columbiana) was tested to enhance the accessibility of the plant cells for the infecting A. tumefaciens strain LBA4404, harboring p35SGUSINT (Boehm et al, 2001). Recently, seedlings of Lotus corniculatus were successfully transformed with a gene encoding the H5N1 hemagglutinin (HA) using Agrobacterium-mediated transformation (Guo et al., 2012).

We obtained 10 transformed duckweed lines after selection from total 14 transformation experiments. This transformed duckweed lines have been multiplied rapidly to generate enough biomass for DNA extraction and analysis of the presence of transgen in the genome of duckweed. 


\section{Macrothink}

Journal of Agricultural Studies

ISSN 2166-0379

2015, Vol. 3, No. 1

Table 5. Summary of transformation experiments into S. polyrhiza

\begin{tabular}{|c|c|c|c|c|c|c|}
\hline \multirow{2}{*}{$\begin{array}{c}\text { No. of } \\
\text { exper. }\end{array}$} & \multirow{2}{*}{$\begin{array}{c}\text { No of tubes were } \\
\text { infected }\end{array}$} & \multicolumn{3}{|c|}{ No of plate was subcultured after } & \multirow{2}{*}{$\begin{array}{c}\text { No of transformed plants survival } \\
\text { after selection }\end{array}$} \\
\cline { 3 - 6 } & 2 times & 3 times & 4 times & 5 times & 0 \\
\hline 1. & 2 & 0 & 0 & & & 0 \\
\hline 2. & 3 & 0 & 0 & & & 0 \\
\hline 3. & 2 & 10 & 0 & & & 3 \\
\hline 4. & 2 & 18 & 17 & 11 & 3 & 0 \\
\hline 5. & 3 & 10 & 0 & & & 0 \\
\hline 6. & 2 & 0 & & & & 0 \\
\hline 7. & 2 & 0 & & & & 3 \\
\hline 8. & 3 & 17 & 26 & 20 & 3 & 0 \\
\hline 9. & 2 & 8 & 2 & 0 & & 0 \\
\hline 10. & 2 & 10 & 3 & 0 & & 0 \\
\hline 11. & 2 & 0 & & & & 2 \\
\hline 12. & 2 & 0 & & & & 0 \\
\hline 13. & 3 & 16 & 13 & 13 & 2 & 0 \\
\hline 14. & 2 & 13 & 7 & 0 & 0 & 0 \\
\hline
\end{tabular}

\subsection{PCR Analysis of Transformed Duckweed Lines}

\subsubsection{Experiment of Hpt Gene}

We have conducted PCR analysis using 10 genomic DNA samples of transformed duckweed as a template and specific primers for amplication of $h p t$ gene with the size of $714 \mathrm{bp}$. The electrophoresis results of PCR products have shown in Figure 2 revealed that: Among 10 DNA samples of transformed plants analyzed have 8 samples appeared DNA band at the position having size $714 \mathrm{bp}$. Therefore, we obtained 8 duckweed lines presence $h p t$ gene from 10 lines of transformed duckweed after many selection cycles.

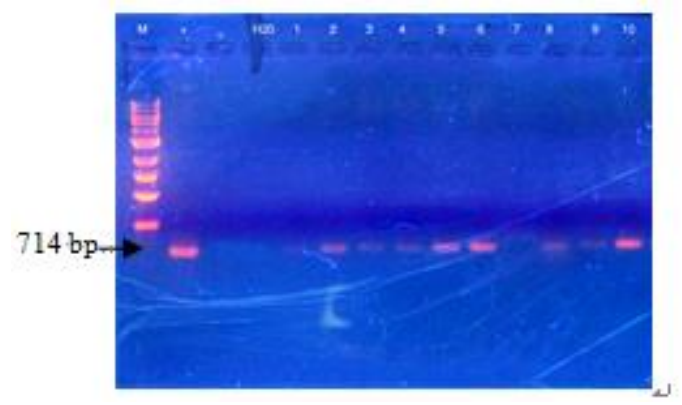

Figure. 2. PCR analysis of transformed duckweed lines for hpt gene

M: Ladder $1 \mathrm{~kb}$ (Fermentas); (+): DNA plasmid p6d35S-UbiHA1; (-): S. polyrrhiza WT (non-transformed); H20; Line $1 ; 2 ; 3 ; 4 ; 5 ; 6 ; 8 ; 9 ; 10 ; 11$ transformed lines having presence of hpt gene; Line 7: transformed line having absence of $h p t$ gene

\subsubsection{Experiment on HA1 gene}

We conducted PCR analysis using DNA samples of 8 duckweed lines and specific primers for amplification HA1 gene 


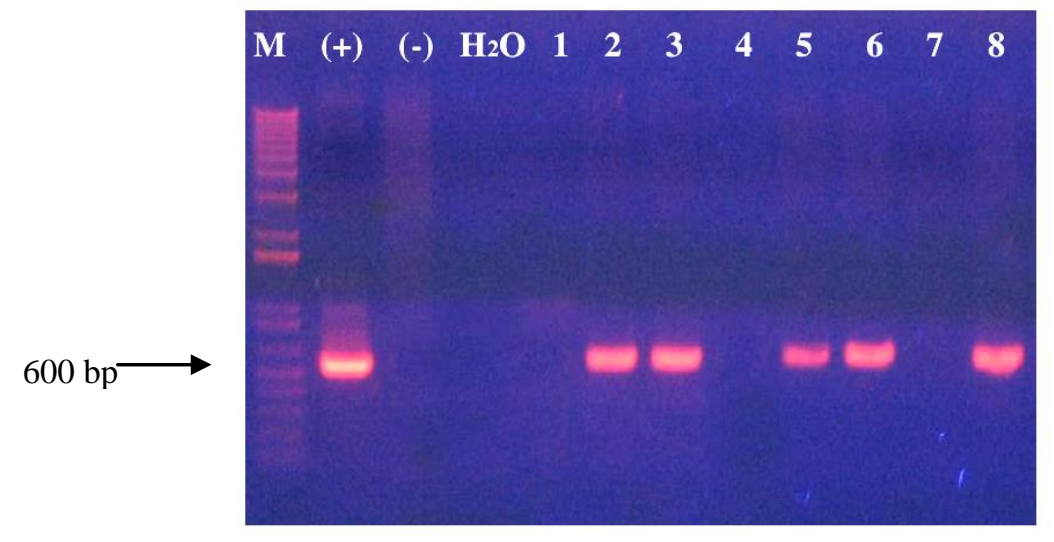

Figure. 3. PCR analysis of transformed duckweed lines for HA1 gene

M: Ladder 1kb (Fermentas); (+1), (+2): DNA plasmid p6d35S-UbiHA1; (-): S. polyrrhiza WT (non-transformed); H20; Line 1; 3; 7; 8: transformed lines having presence of HAl gene; Line 4, 5, 9: transformed line having absence of $H A l$ gene.

The electrophoresis results of PCR products have shown in Figure 3: Among 8 lines of transformed duckweed having positive results with hpt gene had 4 lines to appear DNA band at the position $\sim 600 \mathrm{bp}$ in size. Thus, we have obtained 4 lines with presence of HAl gene from 08 lines of transformed duckweed as templates, these lines are capable of growth and good biomass production which was similar with natural duckweed.

\section{Conclusions}

The culture medium for $S$. polyrhiza duckweed is Hutner medium with reduced mineral concentration $1 / 2(\mathrm{H} / 2)$ supplemented with $10 \mathrm{~g} / 1$ sucrose at $\mathrm{pH}$. This medium showed appropriate for the best growth and development of duckweed. Results of PCR analysis of $S$. polyrhiza lines from 14 transformation experiments that has obtained 4 duckweed lines carrying $H A l$ gene. This prelinary results will be provide the basis for transgenic research in the dukweed species and be useful for further generate the producing enable vaccine via the transgenic plants.

\section{References}

Boehm, R., Kruse, C., Voeste, D., Barth, S., \& Schnabl, H. (2001). A transient transformation system duckweed (Wolffia Columbiana) using Agrobacterium-mediated gene transfer. Journal of Applied Botany, 75,107-111.

Brain, R. A., \& Solomon, K. R. (2007). A protocol for conducting 7-day daily renewal tests with Lemna gibba. Nature Protocols, 2, 979-987.

Caicedo, J. R., Steen, N. P. V. D., Arce, O., \& Gijzen, H. J. (2001). Effect of total ammonia nitrogen concentration and $\mathrm{pH}$ on growth rates of duckweed (Spirodela polyrrhiza). Water Research, 34, 3829-3835.

Daniell, H., Singh, N, D., Mason, H., \& Streatfield, S. J. (2009). Plant-made vaccine antigens 
and biopharmaceuticals. Trend of Plant Sciences, 14, 669-679.

Davoodi, S.A., Samson, N., \& Daniell, H. (2009). A global strategy to combat infectious and autoimmune diseases. Human Vacicines, 5, 488-493.

Franconi, R., Demurtas, O. C., \& Massa, S. (2010). Plant-derived vaccines and other therapeutics produced in contained systems. Expert Review of Vaccines, 9, 877-892

Floss, D. M., Falkenburg D, \& Conrad U. (2007). Production of vaccines and therapeutic antibodies for veterinary applications in transgenic plants: an overview. Transgenic Research, $16,315-332$.

Hutner, S. H. (1975). Comparative physiology in heterotrophic growth in plants. In Growth and differentiation in plants (Loomis WH. ed.), Iowa State, 417-441.

Gomez, E., Zoth, S. C., Carrillo, E., \& Berinstein, A. (2010). Development in plant-based vaccines against disease of concern in developing countries. The Open Infectious Diseases Journal, 4, 55-62.

Guo, Q. Q., Zhang, Z. L., Jiang, S. J., Ma, J. T., Xue, W. T., \& Wu, Y. M. (2012). Expression of an avian influenza virus (H5N1) hemagglutinin gene in transgenic Lotus corniculatus. Plant Molecular Biology Reporter, 30, 1117-1124.

Landolt E. (1986). The family of Lemnacea-a monographic study, Vol. 1. ETH. Stiftung Rybel, Zỹrich, Switzerland.

Landolt E., \& Kandeler R. (1987). The family of Lemnaceae - a monographic study. Vol.2, Veroff. Geobot. Inst. ETH, Zỹrich, Switzerland.

Leng, R. A., Stamboli, J. H., \& Bell, R. (1995). Duckweed- a potential high protein feed resource for domestic animals and fish. Livestock Research for Rural Development, 7.

Les D. H., Crawford D. J., Landdolt E., Gabel J. D., \& Kimball R. T. (2002). Phylogeny and Systematics of Lemnaceae, the Duckweed family. Systematic Botany, 27, 221-240.

Li J., Jain M., Vunsh R., Vishnevetsky J., Hanania U., Flaishman M., Perl A., \& Edelman M. (2004). Callus induction and regeneration in Spirodela and Lemna. Plant Cell Reports, 22, 457-464.

Matvieieva L. N. A., Kishchenko O. M., Shakhovsky A. M., \& Kuchuk M. V. (2011). Agrobacterium rhizogenes-mediate transfer of tuberculosis antigens ESAT6 AND AG85B genes Lemna minor, Biotechnology journal, 4, 46-53, Bibliography 53, Ukrainian.

Nguyen, V. L., Cox, K. M., Ke, J. S., Peele, C. G., Dickey, L. F. (2012).Genetic engineering of a Lemna isoleucine auxotroph. Transgenic Research, 21, 1071-1083.

Mkandawire, M., \& Dudel, E. G. (2005). Accumulation of arsenic in Lemna gibba L. (duckweed) in tailing water of two abandoned uranium mining sites in Saxony, Germany. Sci. Total Environ. 336, 81-89.

Ozengin, N., \& Elmaci, A. (2007). Performance of duckweed (Lemna minor L.) on different 


\section{Macrothink}

types of wastewater treatment. Journal of Environmental Biology, 28, 307-314.

Rahman, M. A., Hasegawa, H., Ueda, K., Maki, T., Okumura C., \& Rahman, M. M. (2007). Arsenic accumulation in duckweed (Spirodela polyrhiza L.): A good option for phytoremediation. Chemosphere, 69, 493-499.

Stomp, A. M. (2005). The duckweed: A valuable plant for biomanufacturing. Biotechnology Annual Review, 11, 69-99.

Stevens, J., Blixt, O., Tumpey, T. M., Taubenberger, J. K., Paulson, J. C., \& Wilson, I. A. (2006). Structure and receptor specificity of the hemagglutinin from an H5N1 influenza virus. Science, 312, 404-410.

Thu, P. T. L., Anh, N. H., Huong, P. T., Hoa, P. T., \& Ham, L. H. (2010). Improvement of transformation procedure into duckweed (Wolffia sp.) through Agrobacterium tumefaciens. Journal of Biotechnology, 8, 53-60.

Wang, W., Kerstetter, R. A., \& Michael, T. P. (2011). Evalution of genome size in duckweeds (Lemnaceae). Journal of Botany, article ID 570319, 9 pages.

Wang, W., Haberer, G., Gundlach, H., Glaber, C., Nussbaumer, T., Luo, M. C., Lomsadze, A., Borodovsky, M., Kerstetter, R. A., Shanklin, J., Nyrant, D. W., Mockler, T. C., Appenroth, K. J., Grimwood, J., Jenkins, J., Chow, J., Choi, C., Adam, C., Cao, X. H., Fuchs, J., Schubert, I., Rokhsar, D., Schmutz, J., Michael, T. P., Mayer, K. F. X, \& Messing, J. (2014). The Spirodela polyrhiza genome reveals insights into its neotenous reduction fast growth and quatic lifestyle. Nature Communications, article No. 3311.

\section{Copyright Disclaimer}

Copyright for this article is retained by the author(s), with first publication rights granted to the journal.

This is an open-access article distributed under the terms and conditions of the Creative Commons Attribution license (http://creativecommons.org/licenses/by/3.0/). 